\title{
Costs of illness analysis in Italian patients with chronic obstructive pulmonary disease (COPD): an update
}

This article was published in the following Dove Press journal:

ClinicoEconomics and Outcomes Research

16 March 2015

Number of times this article has been viewed

\section{Roberto W Dal Negro ${ }^{1,2}$ \\ Luca Bonadiman' \\ Paola Turco ${ }^{2}$ \\ Silvia Tognella ${ }^{3}$ \\ Sergio lannazzo ${ }^{4}$}

'National Center for Respiratory Pharmacoeconomics and Pharmacoepidemiology, Verona, Italy; ${ }^{2}$ Research and Clinical Governance, Verona, Italy; ${ }^{3}$ General Hospital, ULSS

22 Regione Veneto, Bussolengo, Italy; ${ }^{4}$ SIHS Health Economics Consulting, Torino, Italy
Correspondence: RW Dal Negro National Center for Respiratory

Pharmacoeconomics and Pharmacoepidemiology,

Via Gabriele Rossetti, 4 Bussolengo,

37124 Verona, Italy

Email robertodalnegro@gmail.com
Background: Chronic obstructive pulmonary disease (COPD) is a major cause of chronic morbidity and mortality worldwide, and its epidemiological, clinical, and socioeconomic impact is progressively increasing. A first estimate of the economic burden of COPD in Italy was conducted in 2008 (the SIRIO [Social Impact of Respiratory Integrated Outcomes] study). The aim of the present study is to provide an updated picture of the COPD economic burden in Italy.

Methods: Sequential patients presenting at the specialist center for the first time during the period 2008-2012 and with record file complete (demographic, clinical, lung function, and therapeutic data; health care resources consumed in the 12 months before the enrollment and for the 3 subsequent years) were selected from the institutional database.

Results: Two hundred and seventy-five COPD patients fitting the inclusion criteria were selected (226 males; mean age: 70.9 years [standard deviation: \pm 8.4 years]; $45.8 \%$ were from the north, $25.1 \%$ from central Italy, and $29.1 \%$ from south Italy). COPD-related average costs per patient in the 12 months before enrollment were as follows: hospitalization: $€ 1,970$; outpatient care: $€ 463$; pharmaceutical: $€ 499$; and indirect costs: $€ 358$. Average direct costs and total societal costs were $€ 2,932$ and $€ 3,291$, respectively. Direct cost was $€ 2,461$ (hospitalization: $€ 1,570$; outpatient: $€ 344$; and pharmaceutical: $€ 547)$ in the first year of follow-up, while total societal cost was $€ 2,707$. No significant difference was reported in any cost category between sexes.

Conclusion: The therapeutic approach followed in a specialist center, based on the application of clinical guidelines, has been shown to be a highly effective investment for the long-term management of COPD. A small increase of pharmaceutical costs per year allowed a substantial saving in terms of hospitalizations, costs related to outpatient services, and indirect costs.

Keywords: COPD, health costs, pharmacoeconomic, sex dependency

\section{Introduction}

The assessment of the economic burden of chronic disease represents a constant interest point in the agenda of policymakers in national health care systems, who are facing an ever-growing need to reconcile the limited available economic resources with an aging population and the constant addition of new therapeutic options in all health care areas. The economic crisis has worsened the context, with national health care budgets generally shrinking in many European countries.

The Cost of Illness method, initially established by Rice et al, ${ }^{1}$ carried out by means of the measurement of resource consumption and estimation of associated costs, is a useful methodological tool - widely accepted as a descriptive means of the economic burden of a given disease. Data that allow the estimation of such costs should ideally be produced in a real clinical context. The systematic use of real-world evidence data 
is key to the development of credible economic analyses that can be used by institutions for future planning.

Chronic respiratory diseases have a high prevalence and generate important health and societal costs. More specifically, chronic obstructive pulmonary disease (COPD) is a major cause of chronic morbidity and mortality worldwide. The burden of COPD currently appears to be independent of patients' sex, even if, to our knowledge, no study has so far specifically investigated this aspect. COPD's epidemiological, clinical, and socioeconomic impact is constantly increasing, and there are no signs of change in this trend. COPD is projected to be the third leading cause of death in the world by 2030 and seventh as a burden of disease. ${ }^{2}$

In 2008, the Social Impact of Respiratory Integrated Outcomes (SIRIO) study provided the first estimate of the economic burden of respiratory diseases (asthma and COPD) in Italy. The SIRIO study was designed in 2006 as a global outcome study to produce data regarding the socioeconomic impact of the major respiratory diseases (bronchial asthma, COPD, community-acquired pneumonia). ${ }^{3-5}$

The aim of the present study is to provide an updated picture of the economic burden due to COPD in Italy, as well as to investigate the presence of sex-specific differences.

\section{Materials and methods}

The study was an observational, retrospective, and noninterventional study of 3-year duration (the UPDATE study). Sequential patients presenting at the Lung Unit of the Orlandi General Hospital, Italy, for the first time during the period 2008-2012 were automatically selected from the institutional database. Inclusion criteria were as follows: 1) males or females with a diagnosis of COPD according to the Global Initiative for Chronic Obstructive Lung Disease (GOLD) guidelines (2007); ${ }^{6}$ ) age $\geq 40$ years; 3 ) availability of at least one complete clinical record at the first visit, and yearly over the subsequent 3 years; 4 ) the availability of the date of the first and the last referrals and the date of death for those who died during the observational period. The variables collected in all subjects at their first visit were age, sex, smoking status, body mass index (BMI), complete lung function (absolute value, in liters, of the forced expiratory volume in 1 second $\left[\mathrm{FEV}_{1}\right]$ and $\mathrm{FEV}_{1} \%$ predicted values; $\mathrm{FEV}_{1}$ reversibility [changes of basal $\mathrm{FEV}_{1}$ value $30 \mathrm{~min}$ utes after salbutamol $400 \mu \mathrm{g}$ ]; $\mathrm{FEV}_{1}$ /forced vital capacity $[\mathrm{FVC}] \%$ predicted values; $\mathrm{FEV}_{1} /$ vital capacity [VC]; residual volume $[\mathrm{RV}]$; lung transfer of $\mathrm{CO} /$ alveolar volume [TLCO/ VA]; 6-minutes walking test, in meters; Medical Research Council [MRC] dyspnea scale score $;^{7}$ composite index of
Body mass index, airflow Obstruction, Dyspnea, and Exercise [BODE] ${ }^{8}$ and Charlson comorbidity index. ${ }^{9}$ Moreover, health care resources consumed in the 12 months before enrollment in the study and during the follow-up were recorded. Resource data included number of general practitioner (GP) and specialist visits, tests and examinations, total number of exacerbations in the period, access to emergency department, hospital admissions, days in hospital, work days lost, and drug consumption. All subjects gave their informed consent and allowed the use of their personal data for research purposes. Health care resources (in particular, hospitalizations and access to emergency departments) were considered only if related to COPD.

Costs were calculated as mean values per patient in the observation period. Hospital cost was evaluated as the mean cost of intensive care unit and hospital admissions for COPD exacerbation and chronic/acute respiratory failure according to national diagnosis-related group tariffs, ${ }^{10}$ weighted for the frequency reported for each year. GP visit cost was derived from a published cost study, ${ }^{11}$ inflated to 2013 values. ${ }^{12}$ The costs for examinations and for specialist's visits were derived from national inpatient tariffs. ${ }^{13}$ Drug consumption for maintenance and exacerbation management was measured and valued according to current prices. ${ }^{14,15}$ Direct costs were grouped in three categories: 1) hospitalization costs, including drugs administered in hospital to treat severe exacerbations; 2) outpatient costs, including visits, examinations, and ambulatory care; and 3) drug costs for maintenance and exacerbation not requiring hospitalization. Indirect costs were valued in terms of productivity loss occurring as a result of patients' inability to work. They were calculated based on patients' occupational status and average daily wages. ${ }^{16}$

Descriptive statistics were used to analyze the demographic, clinical, and treatment characteristics of the study population. Statistical comparisons were calculated by means of nonparametric tests (Welch's $t$-test) at a statistical significance level of $P<0.05$.

\section{Results}

Two hundred and seventy-five COPD patients fitting the inclusion criteria were selected (226 males; mean age: 70.9 years; standard deviation [SD]: \pm 8.4 ). The overall characteristics of the cohort are reported in Table 1 . The geographical distribution of patients was as follows: $45.8 \%$ from the northern, $25.1 \%$ from the central, and $29.1 \%$ from the southern regions of Italy. In terms of employment status, the most represented category was that of retired persons, while the least represented was that of full-time employees. 
Table I Baseline characteristics of the study population

\begin{tabular}{|c|c|c|c|c|}
\hline & Overall population $(n=275)$ & Males $(n=226)$ & Females $(n=49)$ & $P$-value \\
\hline Age, years & $70.9 \pm 8.4$ & $70.9 \pm 8.1$ & $70.8 \pm 9.4$ & 0.937 \\
\hline BMI & $26.8 \pm 4.6$ & $27.1 \pm 4.6$ & $25.1 \pm 4.3$ & 0.006 \\
\hline \multicolumn{5}{|l|}{ Smoking status } \\
\hline Active smoker & $65(23.6 \%)$ & $47(20.8 \%)$ & $18(36.7 \%)$ & \\
\hline Ex-smoker & $184(66.9 \%)$ & $166(73.4 \%)$ & $18(36.7 \%)$ & \\
\hline Ever smoker & $26(9.5 \%)$ & $13(5.7 \%)$ & $13(26.6 \%)$ & \\
\hline $\mathrm{FEV}_{1}(\mathrm{~L})$ & $1.5 \pm 0.5$ & $1.5 \pm 0.5$ & $1.2 \pm 0.5$ & 0.001 \\
\hline FEV $\%$ pred & $55.9 \pm 18.8$ & $56.1 \pm 19.1$ & $55.3 \pm 17.9$ & 0.785 \\
\hline $\mathrm{FEV}_{\mathrm{I}} / \mathrm{FVC}(\%)$ & $55.9 \pm 10.3$ & $55.6 \pm 10.5$ & $57.2 \pm 9.2$ & 0.675 \\
\hline $\mathrm{FEV}_{1} / \mathrm{VC}$ & $51.1 \pm 10.6$ & $50.7 \pm 10.8$ & $52.8 \pm 9.5$ & 0.206 \\
\hline RV\% pred & $156.9 \pm 46.2$ & $156.5 \pm 47.4$ & $160.4 \pm 37.0$ & 0.596 \\
\hline TLCO/VA\% pred & $70.9 \pm 26.2$ & $70.1 \pm 26.6$ & $75.9 \pm 24.1$ & 0.157 \\
\hline $\mathrm{FEV}$, reversibility & $6.7 \pm 7.9$ & $7.1 \pm 7.9$ & $4.7 \pm 7.4$ & 0.636 \\
\hline $6^{\prime}$ walking test $(\mathrm{m})$ & $233.3 \pm 92.7$ & $237.0 \pm 92.8$ & $216.1 \pm 91.7$ & 0.149 \\
\hline MRC score & $2.3 \pm 1.2$ & $2.3 \pm 1.2$ & $2.4 \pm I .1$ & 0.599 \\
\hline BODE index & $4.4 \pm 2.6$ & $4.3 \pm 2.6$ & $4.8 \pm 2.7$ & 0.224 \\
\hline Charlson comorbidity index & $3.3 \pm 1.8$ & $3.3 \pm 1.8$ & $3.2 \pm 2.0$ & 0.730 \\
\hline
\end{tabular}

Notes: Means \pm SD calculated for each variable at the first visit in the whole sample, in males and females. Statistical comparison is presented by sex (Welch's $t$-test). Abbreviations: 6' walking test, 6-minutes walking test; BMI, body mass index; FEV , forced expiratory volume in I second; FEV , reversibility, changes of basal FEV, value 30 minutes after salbutamol $400 \mu \mathrm{g}$; FVC, forced vital capacity; VC, vital capacity; RV, residual volume; TLCO/VA, lung transfer of CO/alveolar volume; MRC score, Medical Research Council dyspnea scale; BODE index, composite index of Body mass index, airflow Obstruction, Dyspnea, and Exercise; pred, predicted; SD, standard deviation.

With respect to smoking status, current and ex-smokers were the majority of the patient sample, and smoke prevalence was $23.6 \%$.

COPD severity in the cohort ranged from moderate to severe (Figure 1), according to the definition in GOLD guidelines. ${ }^{6}$ At least one comorbidity was present in more than $65 \%$ of patients, and cardiovascular comorbidities were the most represented (35.1\%). Mean ( \pm SD) baseline MRC score was $2.3 \pm 1.2$, while mean $( \pm \mathrm{SD})$ BODE index was $4.4 \pm 2.6$ and mean $( \pm$ SD) Charlson comorbidity index was 3.3 \pm 1.8 . BMI and $\mathrm{FEV}_{1}$ (L) were slightly lower in females.
No other sex-dependent difference was reported among the remaining variables.

Mean per-patient cost at the first visit is reported in Table 2. Direct cost accounted for $89.1 \%$ of the total cost. The total per-patient cost was $€ 3,291$, a value $20.8 \%$ higher than the corresponding figure estimated in $2008(€ 2,724)$ in a similar cohort (in terms of age, sex distribution, and disease severity). ${ }^{4}$ Hospitalization costs represented $59.9 \%$ of the total cost and $67.2 \%$ of the direct cost. These ratios were very similar to those found in 2008 (59.4\% and 64.5\%, respectively). ${ }^{5}$ When compared to 2008 figures, outpatient

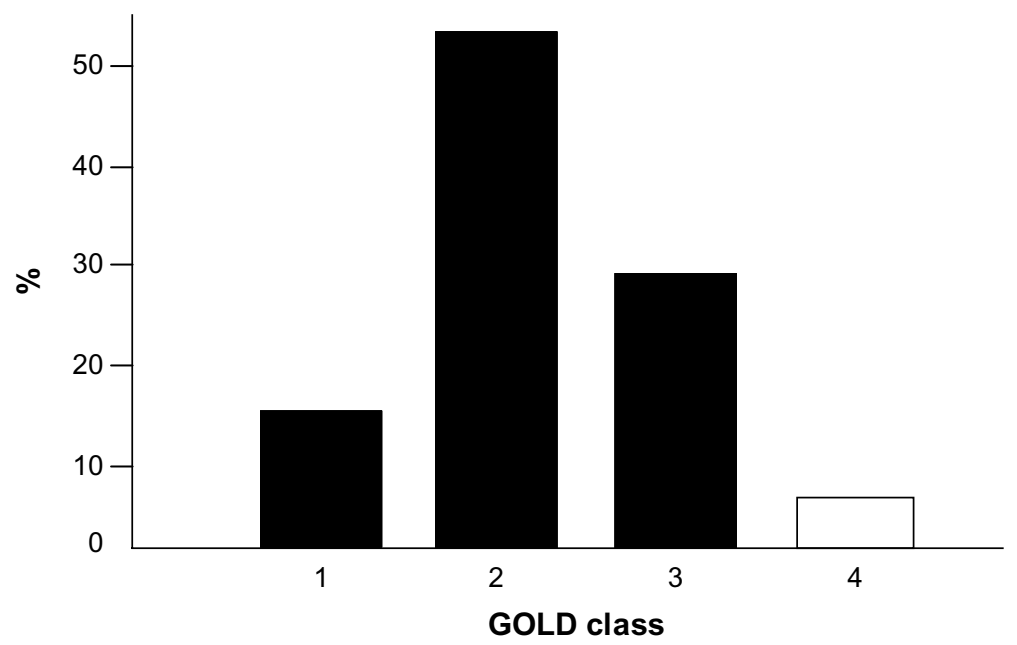

Figure I Baseline distribution of COPD subjects by severity according to the GOLD guideline.

Notes: I: mild; 2: moderate; 3: severe; 4: very severe.

Abbreviations: COPD, chronic obstructive pulmonary disease; GOLD, Global Initiative for Chronic Obstructive Lung Disease. 
Table 2 Direct, indirect, and total mean cost per patient at baseline (I2 months before enrollment) and at I2-month follow-up

\begin{tabular}{|c|c|c|c|}
\hline & $\begin{array}{l}\text { Mean cost (euro) at baseline } \\
\text { ( } 12 \text { months before enrollment) }[95 \% \mathrm{Cl}]\end{array}$ & $\begin{array}{l}\text { Mean cost (euro) at I 2-month } \\
\text { follow-up }[95 \% \mathrm{Cl}]\end{array}$ & $P$-value \\
\hline Direct costs & $2,932.2[2,643.1 ; 3,221.3]$ & $2,460.4[2,332.2 ; 2,588.6]$ & 0.0001 \\
\hline Hospitalization costs & I,970.4 $[968.0 ; 2,972.8]$ & I,569.7[1,427.9; I,7।I.5] & 0.0001 \\
\hline Outpatient costs & $463.2[207.5 ; 718.9]$ & 343.9 [255.1; 432.7] & 0.0001 \\
\hline Pharmaceutical costs & $498.6[252.5 ; 744.7]$ & $546.8[503.8 ; 589.8]$ & ns \\
\hline Indirect costs & 358.5 [119.0; 598.0] & $246.3[189.5 ; 303.1]$ & 0.001 \\
\hline Total costs & $3,290.7[2,539.9 ; 4,051.2]$ & $2,706.7[2,57|.5 ; 2,84| .9]$ & 0.0001 \\
\hline
\end{tabular}

Notes: The containment of both direct (mainly in terms of reduction in hospitalization and outpatient costs) and indirect costs contributed to the substantial drop in total costs due to COPD.

Abbreviations: $\mathrm{Cl}$, confidence interval; COPD, chronic obstructive pulmonary disease; ns, not significant.

costs increased by $29.9 \%$, changing from the $€ 356.7$ cost of 6 years ago to the present value of $€ 463.2$. To the same extent, the cost of pharmacological therapy increased by $43.6 \%$, changing from $€ 347.2$ to the present value of $€ 498$.6. This value corresponds to $17.0 \%$ of the direct cost and $15.1 \%$ of the total cost of illness.

Mean per-patient cost during the 12-month follow-up period is reported in Table 2. When compared with the basal cost (ie, the cost recorded in the 12 months before the enrollment), there is a significant decrease, with a change from $€ 3,290.7$ to $€ 2,706.7$, corresponding to a saving of $€ 584.0$ (17.7\% reduction) $(P<0.0001)$. In the same comparison, the direct cost decreased by $16.1 \%$, corresponding to a saving of $€ 471.8(P<0.0001)$, while indirect costs were lowered by $31.3 \%$, corresponding to a saving of $€ 112.2(P<0.001)$. At the end of the follow-up, direct costs represented $57.9 \%$ of total cost and $63.8 \%$ of direct costs, corresponding to $3 \%-4 \%$ less than that observed at the first visit. Outpatient costs also were substantially decreased by $25.8 \%$, from $€ 463.2$ to $€ 343.9(P<0.0001)$. Differently from other cost categories, pharmaceutical costs increased during the follow-up, even if not in a significant manner $(P=\mathrm{ns})$ (Table 2). The expenses for drugs changed by $9.7 \%$, from $€ 498.6$ to $€ 546.8$. The details of baseline costs by sex are reported in Table 3. No significant difference was reported in any cost category between sexes (all $P=\mathrm{ns}$ ), even though, for females, a general tendency to lower costs was seen for all costs except for pharmaceutical costs.
Costs were also analyzed by stratifying the overall cohort by the ultimate outcome (ie, survival or death) during the complete observation period of the study (at baseline and after 3 years). At baseline, total cost as well as all other costs were much higher in the subgroup of patients who died over the observation period $(n=111)$ with respect to those who survived $(n=164)$ (Table 4). However, except for the pharmaceutical costs that remained unchanged, a significant decrease in total cost was recorded over the 3-year follow-up. This change was substantial and statistically significant across all cost components (all $P<0.001$ ), even if it was essentially due to the decrease in hospitalization costs (Figure 2). This significant trend was registered in both subgroups of patients, independently of their severity and final outcome.

\section{Discussion and conclusion}

In general, data of the UPDATE study demonstrates that the average cost to manage a COPD patient in Italy is still increasing, as compared to what was measured in $2008^{5}$ in a cohort of patients that is comparable in terms of age, sex distribution, and disease severity. Direct cost still represents the major component of total cost (89.1\%), and hospitalization cost still represents the major component of both total $(60.0 \%)$ and direct costs $(67.2 \%)$, without any substantial percentage difference with respect to the same 6 years ago.

The relevance of hospitalization costs in the management of COPD patients is also confirmed by a recent study published by Blasi et al, ${ }^{17}$ which was uniquely calibrated on

Table 3 Mean cost per patient at baseline detailed by sex

\begin{tabular}{lllll}
\hline & $\begin{array}{l}\text { Mean cost (euro) of overall } \\
\text { population }(\mathbf{n = 2 7 5})[\mathbf{9 5 \%} \mathbf{C l}]\end{array}$ & $\begin{array}{l}\text { Mean cost (euro) for } \\
\text { males }(\mathbf{n = 2 2 6})[\mathbf{9 5 \%} \mathbf{C l}]\end{array}$ & $\begin{array}{l}\text { Mean cost (euro) for } \\
\text { females }(\mathbf{n = 4 9})[\mathbf{9 5 \%} \mathbf{C I}]\end{array}$ \\
\hline Hospitalization costs & $1,970.4[968.0 ; 2,972.8]$ & $2,003.3[1,509.6 ; 2,497.0]$ & $1,818.8[1,075.2 ; 2,562.4]$ & $\mathrm{P}$-value \\
Outpatient costs & $463.2[207.5 ; 718.9]$ & $468.0[340.2 ; 595.8]$ & $440.9[296.8 ; 585.0]$ & $\mathrm{ns}$ \\
Pharmaceutical costs & $498.6[252.5 ; 744.7]$ & $490.6[386.1 ; 595.1]$ & $506.2[236.1 ; 776.3]$ & $\mathrm{ns}$ \\
Indirect costs & $358.5[119.0 ; 598.0]$ & $364.8[259.9 ; 469.7]$ & $349.3[102.2 ; 596.4]$ & $\mathrm{ns}$ \\
\hline
\end{tabular}

Abbreviation: $\mathrm{Cl}$, confidence interval; ns, not significant. 
Table 4 Mean costs calculated at the first visit in patients who survived and who died over the 3-year period

\begin{tabular}{|c|c|c|c|}
\hline & $\begin{array}{l}\text { Mean cost (euro) for patients } \\
(\mathrm{n}=164) \text { who survived }[95 \% \mathrm{Cl}]\end{array}$ & $\begin{array}{l}\text { Mean cost (euro) for patients } \\
\text { (n=III) who died }[95 \% \mathrm{CI}]\end{array}$ & $\begin{array}{l}\text { Welch's t-test } \\
P \text {-value }\end{array}$ \\
\hline Hospitalization costs & $673.9[420.6 ; 1,094.6]$ & $3,886.1[3,007.4 ; 4,764.8]$ & 0.001 \\
\hline Outpatient costs & | 47.5 [87.8; 207.7] & $929.5[699.9 ; 1,159.4]$ & 0.001 \\
\hline Pharmaceutical costs & $218.2[134.9 ; 301.5]$ & $809.5[600.7 ; 1,018.3]$ & 0.001 \\
\hline Direct costs & $\mathrm{I}, 039.6[868 . \mathrm{I} ; \mathrm{I}, 2 \mathrm{II} . \mathrm{I}]$ & $5,625.1[5,030.6 ; 6,219.6]$ & 0.001 \\
\hline Indirect costs & $|2| .4[65 .|;| 77.7]$ & $533.8[342.8 ; 724.8]$ & 0.001 \\
\hline Total costs & $\mathrm{I},|\mathrm{I}| \mathrm{I} .0[968.4 ; \mathrm{I}, 353.6]$ & $6,158.9[5,508.0 ; 6,809.8]$ & 0.001 \\
\hline
\end{tabular}

Note: In the brackets, the two figures reported correspond to the lower and the upper confidence limit (ie the interval) of each measure's mean value. Abbreviation: $\mathrm{Cl}$, confidence interval.

the severity and the frequency of exacerbations and on the hospitalization rate. This was a secondary analysis of health care administrative databases of the Lombardy Region in North Italy, which enrolled 15,857 COPD patients hospitalized in 2006 for a severe exacerbation, and followed them for a mean period of 2.4 years.

As a result of the cost analysis, it appears that the average health care resource consumption measured in this sample of severe COPD patients was around $€ 6,700$ per patient-year. When compared to the corresponding cost estimated in the present study in a cohort of COPD patients of different degrees of severity, this cost is more than double. Even if it should be considered that this higher cost was calculated in a sample of older (mean age: 76 years), poorly controlled patients with on average more exacerbations (more than three exacerbations per patient per year vs 1.5 exacerbations per patient per year of the present study), this study confirms the crucial importance of the hospitalization cost, especially in severe COPD patients. However, regardless of the different designs and the difference in illness severity of patients, these two studies are characterized by some main common results. In both studies, the ratio of the hospitalization cost/total direct cost was comparable: $67.2 \%$ in the present study vs $70.7 \%$ in Blasi's study. ${ }^{17}$ Moreover, together with exacerbations, comorbidities play a relevant role in driving both COPD progression and survival. Finally, the total cost tends to decrease over time, likely due to a more appropriate longterm therapeutic strategy following the index date.

In the present study, the mean Italian cost for an outpatient's exacerbation was calculated for the first time to our knowledge, and it corresponds to $€ 460$, which can drop by more than $25 \%$ after an appropriate outpatient treatment over 12 months. As already demonstrated in the past, ${ }^{3-5}$ the more appropriate therapeutic strategy based on the strict application of clinical guidelines is shown to be a highly effective investment for the long-term management of COPD. In fact, even if a cause-effect relationship between the changes in treatment plans and costs still is only a plausible hypothesis, a small increase of pharmaceutical costs per year will result in a substantial saving in terms of cost of exacerbations not requiring hospitalization, indirect costs, and hospitalization.

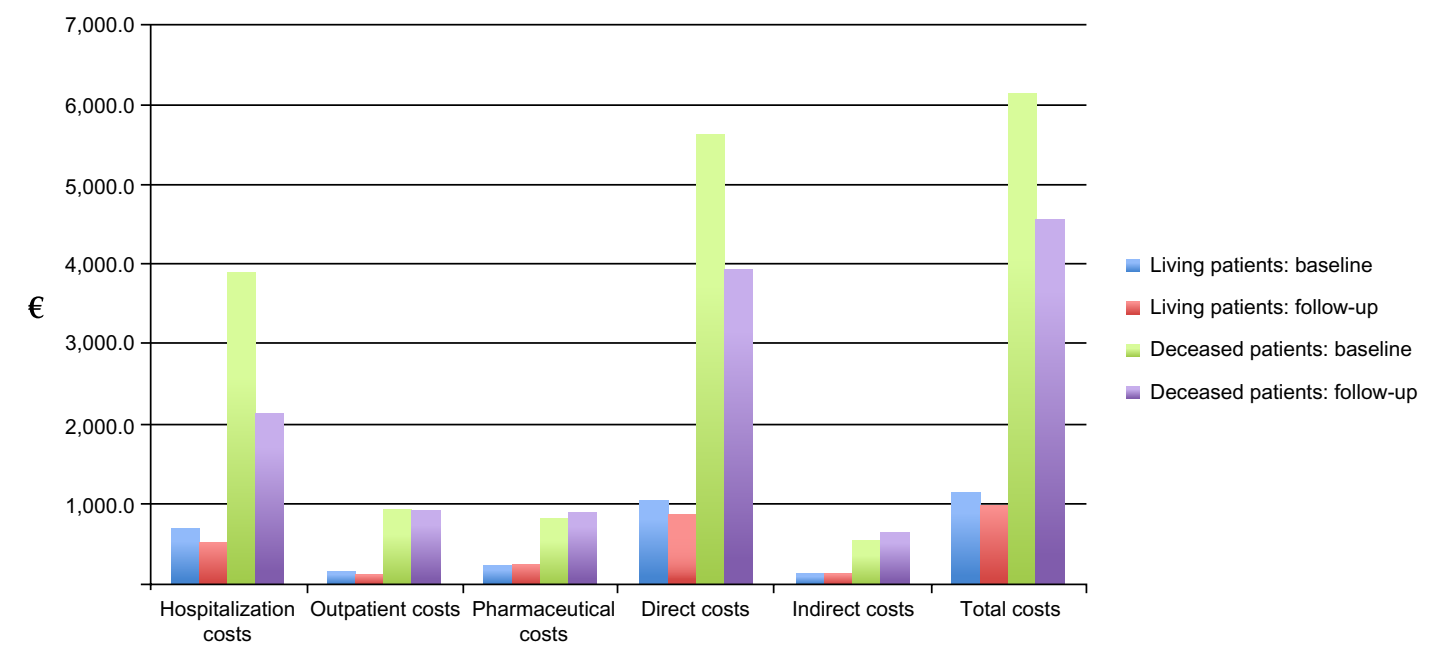

Figure 2 Baseline and I-year follow-up costs by categories stratified by ultimate outcome during the observation period ( 3 years).

Notes: The impact of hospitalization costs in the subgroup of patients who died $(\mathrm{n}=\mathrm{III})$ is dominant over all categories, and their decrease from baseline to follow-up is mode enhanced. 
Finally, no significant sex dependency has been proved in the short- and long-term economic impact of COPD, and non significant differences between sexes were also assessed in terms of clinical and lung function indicators. The appropriate management of COPD is thus equally convenient in males and females, independent of its clinical severity.

Moreover, patients who died did not represent a subgroup of patients in our opinion. Their outcomes and their costs were compared to those of survivors just to emphasize that COPD patients characterized right from baseline by a peculiar pattern (ie, a higher symptom score, several comorbidities, and stronger lung function limitations) are much more likely to show disease progression, leading up to death in a consistent proportion of cases. Thus, early comprehensive evaluation of COPD should be emphasized in real life because it is crucial and strategic in terms of disease progression from the first approach to the patient.

Even if to a smaller extent than in 2002 and 2008,, 3 the results of the UPDATE study confirm that COPD is still mainly managed in the hospital setting in Italy, independently from its intrinsic severity. Economic resources consumed for outpatient care now are confirmed to be higher than those in the past, but these resources still prove insufficient at present for inverting the attitude toward frequent hospitalizations. The burden likely depends on the organization of the Italian health system, which is still not ready for the territorial managements of COPD patients, in particular those having moderate or moderate-to-severe illness. GPs or territorial lung physicians could efficiently manage this type of patient at home and this would produce a substantial decrease of COPD economic impact.

Data from the present study lead to a strong strategic suggestion: health care stakeholders should provide a much more coordinated effort and should support a more coordinated organization for containing the ever-increasing burden of COPD, mainly based on early case finding, outpatient care, and appropriate long-term therapeutic intervention. Only from this evidence and investing based on this strategy, the burden of COPD will be minimized.

Further analytical calculations are in progress, aimed at investigating and comparing standard variables (such as clinical signs, multiple scores, lung function, etc) versus the power of health cost calculations in predicting COPD survival.

\section{Disclosure}

The authors report no conflicts of interest in this work.

\section{References}

1. Rice DP, Hodgson TA, Kopstein AN. The economic costs of illness: a replication and update. Health Care Financ Rev. 1985;7(1):61-70.

2. Mathers CD, Loncar D. Projections of global mortality and burden of disease from 2002 to 2030. PLoS Med. 2006;3(11):e442.

3. Dal Negro R, Berto P, Tognella S, Quareni L; Global Outcomes in Lung Disease Study Group. Cost-of-illness of lung disease in the TriVeneto region, Italy: the GOLD Study. Monaldi Arch Chest Dis. 2002;57(1): 3-9.

4. Dal Negro RW, Micheletto C, Tosatto R, Dionisi M, Turco P, Donner CF. Costs of asthma in Italy: results of the SIRIO (social impact of respiratory integrated outcomes) study. Respir Med. 2007;101(12):2511-2519.

5. Dal Negro RW, Tognella S, Tosatto R, Dionisi M, Turco P, Donner CF. Costs of chronic obstructive pulmonary disease (COPD) in Italy: the SIRIO study (social impact of respiratory integrated outcomes). Respir Med. 2008;102(1):92-101.

6. Global Initiative for Chronic Obstructive Lung Disease. Global Strategy for the Diagnosis, Management, and Prevention of Chronic Obstructive Pulmonary Disease; 2007. Available from: http://www.goldcopd.org/ Guidelines/guidelines-global-strategy-for-diagnosis-management2007.html. Accessed December 10, 2014

7. Bestall JC, Paul EA, Garrod R, Garnham R, Jones PW, Wedzicha JA. Usefulness of the Medical Research Council (MRC) dyspnoea scale as a measure of disability in patients with chronic obstructive pulmonary disease. Thorax. 1999;54(7):581-586.

8. Celli BR, Cote CG, Marin JM, et al. The body-mass index, airflow obstruction, dyspnea, and exercise capacity index in chronic obstructive pulmonary disease. $N$ Engl J Med. 2004;350(10):1005-1012.

9. Charlson ME, Pompei P, Ales KL, MacKenzie CR. A new method of classifying prognostic comorbidity in longitudinal studies: development and validation. J Chronic Dis. 1987;40(5):373-383.

10. Italian Ministry of Health. Tariffe delle prestazioni di assistenza ospedaliera per acuti [DRG tariffs]. Gazzetta Ufficiale della Repubblica Italiana. Serie N.23; Supplemento N.8 del 28 gennaio 2013. Italian.

11. Garattini L, Castelnuovo E, Lanzeni D, Viscarra C. Durata e costo delle visite in medicina generale: il progetto DYSCO [Duration and cost of GP visits]. Farmeconomia e percorsi terapeutici. 2003;4(2):109-114. Italian.

12. Eurostat. Harmonized Indices of Consumer Prices (HICPs) - Health sector; 2014. Available from: http://epp.eurostat.ec.europa.eu/portal/ page/portal/hicp/data/database. Accessed December 10, 2014.

13. Italian Ministry of Health. Tariffe delle prestazioni di assistenza specialistica ambulatoriale. [inpatient tariffs]. Gazzetta Ufficiale della Repubblica Italiana. Serie N.23; Supplemento N.8 del 28 gennaio 2013. Italian.

14. EDRA. [Italian Drug Formulary]. L'Informatore Farmaceutico. Rome: EDRA; 2014.

15. Italian Drug Agency (AIFA). [Generic drug prices]. Lista di trasparenza e relativi prezzi di riferimento; 2014. Available from: http:// www.agenziafarmaco.gov.it/it/content/liste-di-trasparenza-15052014. Accessed December 10, 2014.

16. Eurostat. Eurostat Yearbook - Wages and Labour Costs. Luxembourg: Eurostat; 2013.

17. Blasi F, Cesana G, Conti S, et al. The clinical and economic impact of exacerbations of chronic obstructive pulmonary disease: a cohort of hospitalized patients. PLoS One. 2014;9(6):e101228. 


\section{Publish your work in this journal}

ClinicoEconomics \& Outcomes Research is an international, peerreviewed open-access journal focusing on Health Technology Assessment, Pharmacoeconomics and Outcomes Research in the areas of diagnosis, medical devices, and clinical, surgical and pharmacological intervention. The economic impact of health policy and health systems organization also constitute important areas of coverage. The manuscript management system is completely online and includes a very quick and fair peer-review system, which is all easy to use. Visit http://www.dovepress.com/testimonials.php to read real quotes from published authors.

Submit your manuscript here: http://www.dovepress.com/clinicoeconomics-and-outcomes-research-journal 